\title{
Interventions for prevention of childhood obesity in primary care: a qualitative study
}

\author{
Nicole Bourgeois MSc RD, Paula Brauer PhD, Janis Randall Simpson PhD, Susie Kim MD, Jess Haines PhD
}

See also www.cmaj.ca/lookup/doi/10.1503/cmaj.150854 and www.cmaj.ca/lookup/doi/10.1503/cmaj.160043

\section{Abstract}

Background: Preventing childhood obesity is a public health priority, and primary care is an important setting for early intervention. Authors of a recent national guideline have identified a need for effective primary care interventions for obesity prevention and that parent perspectives on interventions are notably absent from the literature. Our objective was to determine the perspectives of primary care clinicians and parents of children 2-5 years of age on the implementation of an obesity prevention intervention within team-based primary care to inform intervention implementation.

Methods: We conducted focus groups with interprofessional primary care clinicians $(n=40)$ and interviews with parents $(n=26)$. Participants were asked about facilitators and barriers to, and recommendations for implementing a prevention program in primary care. Data were recorded and transcribed, and we used directed content analysis to identify major themes.

Results: Barriers existed to addressing obesity-related behaviours in this age group and included a gap in well-child primary care between ages 18 months and 4-5 years, lack of time and sensitivity of the topic. Trust and existing relationships with primary care clinicians were facilitators to program implementation. Offering separate programs for parents and children, and addressing both general parenting topics and obesity-related behaviours were identified as desirable.

Interpretation: Despite barriers to addressing obesity-related behaviours within well-child primary care, both clinicians and parents expressed interest in interventions in primary care settings. Next steps should include pilot studies to identify feasible strategies for intervention implementation.

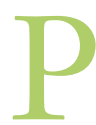
revention of childhood obesity is an important public health priority, given the high prevalence of obesity in Canadian children as young as 2-5 years of age,,$^{1-3}$ and the associated health risks when obesity persists in adulthood. ${ }^{47}$ Leaders in the field have expressed a need for systems-wide prevention strategies ${ }^{8,9}$ and have identified primary care as an important setting, given the wide population reach and frequent contact with primary care in the early years. ${ }^{10}$ In their recently published guideline on the prevention and management of obesity in children in primary care, the Canadian Task Force on Preventive Health Care recommended against offering structured prevention interventions in the primary care setting because of a dearth of evidence for effective interventions. ${ }^{11}$ The task force also identified a lack of knowledge of parents' and children's preferences regarding interventions. Formative research within the primary care setting is needed to understand the current context and resources available to support possible interventions, ${ }^{12}$ and to identify preferences of the end-users of the intervention. This information can inform the development and refinement of interventions for obesity prevention. ${ }^{13}$
Our study aimed to determine the perspectives of primary care clinicians and the parents of their 2- to 5-year-old patients on an intervention for obesity prevention within primary care, through the lens of an existing universal prevention intervention developed by the senior investigator (J.H.). The 9-week structured group intervention targets parents of children $2-5$ years of age as the primary agents of behaviour change, and embeds weight-related behaviours within an empirically tested general parenting skills program. ${ }^{14}$ The intervention includes a concurrent children's program to act as a catalyst for parent participation. The intervention has been tested in communitybased settings in both the United States and Canada ${ }^{14}$ but has not yet been delivered within the primary care setting.

\section{Competing interests: None declared.}

This article has been peer reviewed.

Correspondence to: Nicole Bourgeois, nicole.bourgeois@ wchospital.ca CMAJ Open 2016. DOI:10.9778/cmajo.20150081 


\section{Methods}

\section{Study design and setting}

We used a qualitative approach involving focus groups with clinicians and individual interviews with parents to determine preferences with respect to prevention interventions in the primary care setting.

This study was conducted in 3 primary care Family Health Teams in Ontario. In these teams, physicians work in groups under a blended capitation model and are supported by interprofessional health care providers. ${ }^{15}$ Our sites included 1 urban academic practice (18 000 patients, 30 family physicians, 30 residents), 1 urban community-based practice (280 000 patients, 150 family physicians) and 1 rural practice (14 000 patients, 6 family physicians).

\section{Recruitment of participants}

Interprofessional clinician participants with higher proportions of patients in the target age were purposively approached to participate via email. It is unknown how many clinicians refused to participate; clinicians were instructed to respond via email to the researcher if they were interested in participating. Clinicians provided informed consent at the focus groups.

At each site, parent participants were purposively recruited through several mechanisms, which included flyers (posted in waiting rooms and distributed by staff) and letters sent to parents through a primary school (rural site only). Thirty-six parents contacted us regarding the study: 10 parents did not complete the interview (1 parent had a baby during the study period, 2 parents were too busy to complete the interview, and we lost touch with 7 parents after follow-up emails before the interview was scheduled). Parents were sent consent forms in advance by mail or email and were provided with a $\$ 35$ grocery gift card for participation. Ethics approval was obtained from the Research Ethics Boards at Women's College Hospital and the University of Guelph.

\section{Data collection and analysis}

We conducted semistructured interviews with parents by telephone and focus groups with interprofessional primary care clinicians at their respective clinics. All clinician focus groups were conducted in person except for 1 that was conducted via telephone and ranged in length from 25 to 60 minutes. All parent interviews were conducted via telephone except for 1 that was done in person at the clinic and ranged in length from 20 to 40 minutes; telephone interviews were chosen because of the geographic dispersion of study sites. All participants completed a brief demographics form.

One of the authors (N.B.) conducted all interviews and focus groups between August 2013 and July 2014. All participants were informed that the research team was considering the implementation of a program for parents of children 2-5 years of age in the Family Health Team and that their input would help inform the tailoring and implementation of the program. The interviewer was a dietitian at 1 of the study sites and, therefore, had working relationships with those clinicians, and 1 parent participant was a former patient. The interviewer had no prior relationships with participants at the other sites. For the clinician focus groups, the interviewer was introduced as a dietitian working in a Family Health Team and may have been seen as an insider to clinicians. With the exception of 1 participant, parents did not know the interviewer's role or background.

Interview guides (Appendix 1, available at www.cmajopen. $\mathrm{ca} /$ content/4/2/E194/suppl/DC1) were based heavily on the original guide created by the senior investigator in the development of the proposed intervention. To focus the discussions, we began clinician focus groups with a description of the proposed intervention and outlined topics to be covered (i.e., physical activity, sleep duration, TV/screen time, limiting sugarsweetened beverages, children's hunger/satiety cues and alternatives to food as rewards). We then asked about current practices in addressing these weight-related behaviours, and the facilitators and barriers to implementing the described program in the participants' primary care setting (Box 1). We conducted parent interviews similarly, except that the program was positioned as a program to support happy, healthy children (i.e., did not discuss obesity or weight).

Contact summary sheets were created after each interview and focus group. ${ }^{16}$ A debriefing was held between the interviewer and a research assistant after the focus groups were conducted to combine detailed notes. All focus group and interview data were audio-recorded and transcribed verbatim by the research assistant. Theoretical saturation was assessed by consensus (interviewer, senior investigator, research assistant), at which point data collection ended. Qualitative analysis software (NViVo) was used for all coding procedures, and we used directed content analytic methods. ${ }^{17} \mathrm{We}$ employed an a priori coding scheme based on the interview guides, and the key foci were current practices in addressing weight-related behaviours, facilitators and barriers to implementation of the proposed intervention in primary care settings, and general recommendations for implementation in primary care. A single analyst (N.B.) read and coded each transcript line-by-line. To assess reliability, a second coder independently coded $25 \%$ of the

Box 1: Relevant questions from the clinician interview guide

- Current practices in addressing weight-related behaviours: Do you routinely offer anticipatory guidance on healthy behaviours? Which healthy behaviours do you typically address with parents? Are there any barriers you find in counselling parents on healthy behaviours in the clinical/office setting?

- Opinions on the proposed intervention: Are the topics covered in the program challenges that you think will fit with the patients in your practice? As a clinician, are these topics you would like your patients to learn more about? Is there anything missing in the topics that you think we should include?

- Intervention implementation: Are there any differences between offering a program in primary care, compared to another setting (i.e. public health)? Are there any features of the primary care setting that would increase the chance that parents would attend the program? What are some ways we can encourage parents to attend the program? What do you think would be the most important factors that determine whether a parent would attend the program? 


\section{OPEN}

Research

transcripts. Average agreement (\%) between the 2 coders was calculated by the software. There was a high level of agreement for both parent interviews (99.5\%) and clinician focus groups (99.3\%). All discrepancies were discussed and resolved between the coders before analysis. To check the validity of interpretation, the second coder was also provided with a selection of individual codes for independent interpretation, which were compared with those of the primary analyst. Interpretations were found to be consistent between coders. To member check our results, clinician participants ( 1 physician, 1 nurse, 1 nurse practitioner) reviewed the results and confirmed that interpretations reflected their experiences.

\section{Results}

\section{Participant characteristics}

Seven clinician focus groups were conducted across the 3 sites $(n=40)$. Attendance ranged from 2 to 13 participants, based on clinician availability on the day of the focus group. The highest participation was from registered nurses; however, a variety of disciplines participated (Table 1). Clinician participants had been in practice from less than 1 to 48 years, and half of them reported that this age group represented at least $10 \%$ of their patients.

Twenty-six parent interviews were conducted across the 3 sites. Theoretical saturation was reached after the 6th rural interview. All of the parent participants were female, and most were white (Table 2).

\section{Themes}

Results are presented in 4 main themes derived from the coding scheme: current practices of primary care clinicians in addressing weight-related behaviours, facilitators to implementation of the proposed intervention in primary care settings, barriers to implementation and recommendations for implementation in primary care.

\section{Current practices of primary care clinicians in addressing weight-related behaviours}

Clinicians were asked about their current practices with respect to weight-related behaviours in children 2-5 years of age (i.e., TV/screen time, physical activity, sugar-sweetened beverages, sleep duration and children's hunger/satiety cues). The extent to which clinicians reported addressing these topics with families in an anticipatory way varied. Many clinicians described addressing some of the weight-related topics routinely. Across and within sites, there was a lack of consistency in what clinicians were routinely addressing. As one participant said, "I think [Clinician] is starting to talk more about sugar-sweetened beverages ... but probably not everyone".

Clinicians identified several barriers to addressing these behaviours with young children. Across all sites, clinicians described a perceived gap in well-child primary care between 2-5 years of age, which corresponds to the immunization schedule in Ontario. Additional barriers to addressing these topics included a lack of time, perceived lack of parental engagement, sensitivity of these topics, and a perceived gap in topics outlined in primary care screening tools (Box 2).

Table 1: Clinician particpant characteristics

\begin{tabular}{|c|c|c|c|c|}
\hline Characteristic & $\begin{array}{l}\text { All sites } \\
n=40\end{array}$ & $\begin{array}{c}\text { Academic site } \\
\quad n=13\end{array}$ & $\begin{array}{c}\text { Rural site } \\
n=13\end{array}$ & $\begin{array}{c}\text { Urban site } \\
\quad n=14\end{array}$ \\
\hline Age, yr; mean \pm SD & $41 \pm 13$ & $43 \pm 12$ & $39 \pm 15$ & $42 \pm 11$ \\
\hline Physician & $6(15.0)$ & $4(30.8)$ & $1(7.7)$ & $1(7.1)$ \\
\hline Registered nurse & $14(35.0)$ & $7(53.8)$ & $2(15.4)$ & $5(35.7)$ \\
\hline Registered dietitian & $3(7.5)$ & - & $1(7.7)$ & $2(14.3)$ \\
\hline Social worker & $2(5.0)$ & - & - & $2(14.3)$ \\
\hline Registered practical nurse & $5(12.5)$ & - & $4(30.8)$ & $1(7.1)$ \\
\hline Other ${ }^{*}$ & $4(10.0)$ & - & $3(23.1)$ & $1(7.1)$ \\
\hline Years in practice, mean \pm SD & $15 \pm 13$ & $17 \pm 12$ & $17 \pm 16$ & $13 \pm 12$ \\
\hline $21 \leq 30$ & 10.0 & 7.7 & - & 21.4 \\
\hline $31 \leq 40$ & 5.0 & 7.7 & 7.7 & - \\
\hline$>40$ & 5.0 & - & - & 14.3 \\
\hline Unknown & 17.5 & 7.7 & 23.1 & 21.4 \\
\hline
\end{tabular}


Facilitators to implementation of the proposed intervention in primary care settings

Both clinicians and parents identified that trust and the longitudinal relationships offered in primary care settings are key facilitators to intervention implementation. Several parents across sites also identified their primary care providers as experts and credible sources of information (Box 3). However, there were a few parents who associated their primary care teams with routine care and not preventative group programs: one parent shared "I only go there for check-ups".

Clinicians and parents also felt that the proposed topics were relevant, and the peer support and learning offered in a group intervention was also perceived to be advantageous (Box 4). Having separate parent and children's programs, and addressing both general parenting topics and weight-related behaviours were identified by parents as desirable aspects of a primary care prevention intervention (Box 5).

\section{Barriers to implementation of the proposed intervention in primary care settings}

The primary barriers identified by both clinicians and parents included that a 9-week intervention may be too long for families, and that availability of transportation and travel time to the clinic may impact attendance. However, parents had variable opinions on the length of the program, with some parents preferring the full 9-week intervention. Clinicians across all sites had concerns that clinics may not have sufficient human resources to implement the intervention.

\section{Recommendations for implementation in primary care}

Across all sites, clinicians identified that some of the weightrelated behaviours may already be established in children $2-5$ years of age. Clinicians at 2 of the sites suggested that the target age range be expanded to include children $0-2$ years of age.

Both clinicians and parents identified that a recommendation from a primary care clinician would be an effective recruitment strategy. The well-attended 18 -month visit was also felt to be a good opportunity to recruit. Across sites, there was some clinician interest in a communication mechanism from the intervention back to the primary care team, so that follow-up could be arranged as needed.

In an early focus group, a clinician recommended an online delivery mode to reduce barriers to participation. Interest in online formats was assessed in subsequent focus groups and interviews; however, most clinicians and parents expressed negative views and preferred in-person interventions. Several parents expressed interest in complementary online materials but not online formats as a primary delivery mode.

\section{Interpretation}

We found that both clinicians and parents were interested in these prevention interventions for the promotion of healthful weight-related behaviours and that the trust and existing relationships offered in primary care settings are facilitators to offering interventions for young families. However, several barriers existed to addressing these behaviours in the context of current well-child primary care visits.

Barriers to addressing weight-related behaviours, such as a lack of time, ${ }^{18,19}$ competing priorities during well-child visits ${ }^{19}$ and sensitivity of these issues, ${ }^{20}$ have also been reported in primary care settings outside of Canada. Insufficient human resources are a key challenge to implementing interventions in this setting. For physicians and nurses who traditionally provide the majority of well-child primary care, it may not be feasible to address multiple weight-related behaviours in the context of a well-child visit. In fact, research has shown that parent retention of anticipatory guidance declines with increasing number of topics addressed. ${ }^{21}$ Adding topics to an already full well-child visit may not be effective. In a review of models of well-child care, Coker and colleagues ${ }^{22}$ found that group visits were at least as effective as individual visits. Our findings suggest that parents and primary care clinicians may be interested in group-based formats for obesity prevention interventions owing to peer learning and support. Expanding the role of nurses in well-child care to include group programs, using other members of the interprofessional primary care team (e.g.,

\begin{tabular}{|lcccc|}
\hline \multicolumn{4}{|c|}{ Table 2: Parent participant characteristics } \\
\hline & $\begin{array}{c}\text { All sites } \\
n=24^{*}\end{array}$ & $\begin{array}{c}\text { Academic } \\
\text { site } \\
n=9\end{array}$ & $\begin{array}{c}\text { Rural site } \\
n=6\end{array}$ & $\begin{array}{c}\text { Urban site } \\
n=9\end{array}$ \\
\hline Characteristic & $33 \pm 5$ & $33 \pm 6$ & $33 \pm 3$ & $33 \pm 5$ \\
\hline Age, yr; mean \pm SD & 100.0 & 100.0 & 100.0 & 100.0 \\
\hline Female sex, \% & $2 \pm 1$ & $2 \pm 1$ & $3 \pm 1$ & $2 \pm 1$ \\
\hline No. of children, mean \pm SD & & & & \\
\hline Ethnic origin, \% & 83.2 & 77.8 & 100.0 & 77.8 \\
\hline White & 4.2 & 11.1 & - & - \\
\hline Asian & 8.3 & 11.1 & - & 11.1 \\
\hline South Asian & 4.2 & - & - & 11.1 \\
\hline First Nations & & & \\
\hline *Two parents did not complete a demographics form. & & \\
\hline
\end{tabular}


social workers, childhood development specialists ${ }^{22}$ or registered dietitians) and/or partnering with public health ${ }^{8}$ could help to overcome barriers related to human resources.

We found that clinicians perceived that tools used to guide well-child care at present do not include guidance on many weight-related behaviours. Recently revised versions of these tools, such as the Rourke Baby Record, have included screening items on some topics (i.e., physical activity/sedentary behaviour, sleep habits and sweetened beverages ${ }^{23}$ ). However,

\section{Box 2: Clinician-reported barriers to addressing weight and} related behaviours with parents of children 2-5 years of age

- Gap in care: “... traditionally we see kids up to the two-yearold because that's their last inoculation or ... eighteen months. So we don't actually see them.... until they go to school ... there's that gap in their care ... traditionally [in] family practice."

- Parent disinterest: "I find like half the parents don't listen to the advice we give to them during those well-baby visits anyway."

- Sensitivity of topics: “... parents don't like to hear that maybe they're doing something ... wrong I guess. You have to really tread delicately and ... you don't want to get their backs up."

- Gaps in screening tools: "... the weight-related topics are all stuff that people ... would be interested in and we try to promote. ...The TV stuff comes up for me a lot ... especially because it's on the Grieg and part of your screening with older kids. But I don't think we talk about it as much on the Rourke with the two to five year olds."

Box 3: Trust, relationships and credibility in the primary care setting

\section{Clinician perspectives:}

- “... there's power in having our own staff running it because we know the patients. ... The longitudinal relationship will come in there."

- "[Patients] prefer coming to their own clinic ... their home base, where they know somebody that may be running it."

- "... [Patients] trust the staff, they trust the nurses, they trust the people here so ... that familiarity ... that would be ... an advantage."

- "...We see them for short periods of time and that is effective. However, this [intervention] ... sort of spreads out. ... I see it fanning out to [increase] our ability to reach them in those short visits. ... We're only seeing them for fifteen minutes. How much can we really get accomplished? And there's a lot do to prevent obesity."

\section{Parent perspectives:}

- "I feel that when you're with the family health team ... you have a connection to that team. You know they're there to take care of you so maybe there's a little bit more feeling of immediate trust. There's no necessary need to develop rapport."

- "Perhaps the reputability ... the information is probably going to be better ... health professions may be able to provide real in-depth information as opposed to just presenting you with a general broad overview."

- "... Definitely has a prestige factor to it, so I think it would entice people more. ... They might be feel it's more scientifically-driven ... and more serious."

- "I would be a lot more likely to go to my doctor's office for it." it is possible that the newest versions have not yet been adopted in some practices. Future research could explore how these revised tools, and others such as Nutrition Screening Tool for Every Preschooler (NutriSTEP), ${ }^{24}$ impact clinical care regarding obesity-related behaviours among children.

We also found that clinicians perceived a gap in care for children between 2-5 years of age, which presents a barrier to addressing weight-related behaviours. Some of these behaviours could be addressed in children before they reach 2 years of age. Future studies should explore optimal timing and frequency of addressing these behaviours.

Our findings offer guidance about structured interventions for families with young children in primary care. Desirable aspects of an intervention included having separate programs for parents and children, and addressing both general parenting topics and weight-related behaviours. Positioning interventions within a general parenting program has been described by oth-

\section{Box 4: Benefits of peer support and group learning}

\section{Clinician perspectives:}

- "So is there value, though, to having that information being repeated in a group setting because ... I think listen to their peers. ... Not necessarily more so than us, but I think they get ... different messages from [their peers], and maybe more meaningful."

\section{Parent perspectives:}

- "... it's always nice to go with a group though and be able to run situations by other people and kind of get input from other parents and a professional on how you could have handled it or what you should do in the future if it keeps coming up.... That's what I find group things are the best for is ... the brainstorming part of it. To share it with people."

- A lot of people don't necessarily have the community right around them ... [parents can] feel like they're the only ones going through ... hard times with a toddler that's just not listening."

Box 5: Desirable features of the intervention (parents):

On the integration of general parenting and healthy lifestyle topics (weight-related behaviours):

- "I like that there's ... the sleep stuff, the eating stuff ... and physical activity. But I also like that there's the psychological stuff as well in terms of disciplining."

- "It would be nice to sort of have a dedicated ... parenting group or class that ... focuses on health issues but also ... general issues."

On the benefits of engaging children in separate, parallel programming:

- “... if l've got [my son] running around and [my other son] on my lap and squirming, I can't pay attention to anything that's going on."

- "Most programs ... it's the children and mothers usually interact. ... But ... [in the proposed intervention] it's really great too because you're ... guaranteed at least a little bit of time just for yourself, right?"

- "... I may get something out of it but then also, he's playing for an hour and a bit which is more fun for him ... than like at home ... So I think that, that to me is a major pull." 
ers as a strategy to increase parent participation ${ }^{25}$ and could be tested in future studies.

\section{Limitations}

Although we engaged with a variety of primary care clinicians from 3 different settings (urban academic, urban and rural), we only recruited from the Family Health Team model, which does not reflect the diversity of practices in Canada and limits the generalizability of our findings. Our sample size for parent participants was small, and parents were not diverse with respect to age, gender or ethnic origin despite an extended recruitment phase, which also limits the generalizability of our findings. Future studies should recruit a wider variety of primary care practices and parents of different ethnic origins to better reflect the Canadian population and to identify if there are important differences in the needs of various groups.

\section{Conclusion}

Effective, engaging interventions for obesity prevention are needed for young children: primary care settings have a wide population reach at a time when they are already engaged in routine care. Although no existing interventions have shown effectiveness, our study provides insight into the preferences of both primary care clinicians and parents, which can inform strategies for obesity prevention within primary care.

\section{References}

1. Roberts, KC, Shields, M, de Groh, M, et al. Overweight and obesity in children and adolescents: results from the 2009 to 2011 Canadian Health Measures Survey. Ottawa: Statistics Canada; 2015. Available: www.statcan.gc.ca/pub/82 -003-x/2012003/article/11706-eng.htm (accessed 2016 Apr. 8).

2. Shields M, Tremblay MS. Canadian childhood obesity estimates based on WHO, IOTF and CDC cut-points. Int 7 Pediatr Obes 2010;5:265-73.

3. Canning PM, Courage ML, Frizzell LM. Prevalence of overweight and obesity in a provincial population of Canadian preschool children. CMA7 2004;171:240-2.

4. Reilly JJ, Kelly J. Long-term impact of overweight and obesity in childhood and adolescence on morbidity and premature mortality in adulthood: systematic review. Int 7 Obes (Lond) 2011:35:891-8.

5. Freedman DS, Khan LK, Dietz WH, et al. Relationship of childhood obesity to coronary heart disease risk factors in adulthood: the Bogalusa Heart Study. Pediatrics 2001;108:712-8.

6. Monteiro PO, Victora CG. Rapid growth in infancy and childhood and obesity in later life-a systematic review. Obes Rev 2005;6:143-54.

7. Guo SS, Huang C, Maynard LM, et al. Body mass index during childhood, adolescence and young adulthood in relation to adult overweight and adiposity: the Fels Longitudinal Study. Int 7 Obes Relat Metab Disord 2000;24:1628-35.

8. Summerbell C, Brown T. Childhood obesity: the guideline for primary care should form part of a whole-system approach. CMA7 2015;187:389-90.

9. Dietz WH, Baur LA, Hall K, et al. Management of obesity: improvement of health-care training and systems for prevention and care. Lancet 2015;385: 2521-33.

10. Gillman MW, Ludwig DS. How early should obesity prevention start? N Engl 7 Med 2013;369:2173-5.
11. Canadian Task Force on Preventive Health Care. Recommendations for growth monitoring, and prevention and management of overweight and obesity in children and youth in primary care. CMA7 2015;187:411-21.

12. Gittelsohn J, Evans M, Story M, et al. Multisite formative assessment for the Pathways study to prevent obesity in American Indian schoolchildren. Am 7 Clin Nutr 1999;69:767S-72S

13. Dehar MA, Casswell S, Duignan P. Formative and process evaluation of health promotion and disease prevention programs. Eval Rev 1993;17:204-20.

14. Haines J, Mayorga AM, McDonald J, et al. Embedding weight-related messages within a general parenting programme: development and feasibility evaluation of parents and tots together. Early Child Dev Care 2012;182:951-65.

15. Family Health Teams. Toronto: Ministry of Health and Long-Term Care; 2014 Available: www.health.gov.on.ca/en/pro/programs/fht/ (accessed 2015 June 9).

16. Miles, MB, Huberman, AM. Qualitative data analysis: an expanded sourcebook. Holland R, editor. Thousand Oaks (CA): Sage Publications; 1994.

17. Berg, BL. Qualitative research methods for the social sciences. Boston: Allyn \& Bacon; 2009.

18. Hearn LA, Miller MR, Campbell-Pope R. Review of evidence to guide primary health care policy and practice to prevent childhood obesity. Med 7 Aust 2008;188:S87-91.

19. Robinson A, Denney-Wilson E, Laws R, et al. Child obesity prevention in primary health care: investigating practice nurse roles, attitudes and current practices. 7 Paediatr Child Health 2013;49:E294-9.

20. Hearn LA, Miller MR, Campbell-Pope R. Review of evidence to guide primary health care policy and practice to prevent childhood obesity. Med 7 Aust 2008;188(Suppl):S87-91.

21. Barkin SL, Scheindlin B, Brown C, et al. Anticipatory guidance topics: are more better? Ambul Pediatr 2005;5:372-6.

22. Coker TR, Windon A, Moreno C, et al. Well-child care clinical practice redesign for young children: a systematic review of strategies and tools. Pediatrics 2013; 131(Suppl 1):S5-25.

23. Rourke L, Leduc D, Rourke J. The Rourke Baby Record. Available: www.rourke babyrecord.ca/downloads.asp (accessed 2015 Dec. 9).

24. Randall Simpson JA, Keller HH, Rysdale LA, et al. Nutrition Screening Tool for Every Preschooler (NutriSTEP): validation and test-retest reliability of a parent-administered questionnaire assessing nutrition risk of preschoolers. Eur f Clin Nutr 2008;62:770-80.

25. Jago R, Sebire SJ, Bentley GF, et al. Process evaluation of the Teamplay parenting intervention pilot: implications for recruitment, retention and course refinement. BMC Public Health 2013;13:1102.

Affiliations: Department of Family Relations and Applied Nutrition (Bourgeois, Brauer, Randall Simpson, Haines), University of Guelph, Guelph, Ont.; Family Practice Health Centre (Bourgeois, Kim), Women's College Hospital; Department of Family and Community Medicine (Kim), University of Toronto, Toronto, Ont.

Contributors: Nicole Bourgeois, Jess Haines, Paula Brauer and Janis Randall Simpson contributed to the study design. Nicole Bourgeois conducted the data collection, and Nicole Bourgeois and Jess Haines conducted the qualitative analysis. All authors contributed to the analysis and interpretation of the data, reviewed the manuscript critically for intellecctual content, gave final approval for the version to be published and agreed to act as guarantors of the work.

Funding: Funding for this study was provided by the University of Guelph, Guelph, Ont.

Acknowledgement: The authors would like to thank Katie Kizis (research assistant) for her assistance with the focus groups, data transcription and reliability testing.

Supplemental information: For reviewer comments and the original submission of this manuscript, please see www.cmajopen.ca/content/4/2/ E194/suppl/DC1 